\title{
Shared collections to shared storage: the CARM1 and CARM2 print repositories
}

Ms. CATHIE JILOVSKY

Chief Information Officer

CAVAL Ltd., Australia

Associate Professor PAUL GENONI

Head of the Dept. of Information Studies

Curtin University, Australia 


\section{Introduction}

In recent years there has been a notable shift with regard to the collaborative management of collections. The most obvious change has been that libraries have needed to find ways to work collaboratively for the acquisition of leased databases of digital content. This has seen the development of numerous different types and sizes of consortia that enable libraries to receive immediate benefits in terms of pricing and content for database subscriptions.

It is the transforming effect of these large-scale database subscriptions that has also brought about changes in collaboration with regard to print management. As collection development activities have moved from print items to digital content, there has been a resulting shift in the focus of collaborative print management from collection development (reducing duplication in a library system by developing areas of complementary collection strength) to collection redundancy (reducing the space required by print collections by either managed disposal or shared storage). A number of models have been developed in order to manage redundancy of print collections, but almost certainly the most efficient in terms of costs to a library system is that of collaborative print repositories. Although libraries might choose to reduce their print storage costs by having joint use of a storage facility, the greatest efficiencies are achieved when they elect to cede ownership of items to an independently managed print repository, and these permanently retained copies are then used as the basis for system-wide de-duplication and disposal.

Constance Malpas has reported on in-depth studies undertaken by OCLC Research, and predicted that 'print repositories will emerge as an acceptable and even preferred alternative to local management' (Malpas 2011). Malpas outlines a vision of virtual collections created through a linked network of print repositories and individual libraries. Although based on data and holdings from US collections the initiative could potentially be the basis for international cooperation and provide a way to build on existing library investments in print collections in a digital age.

An approach to shared storage based on ceded ownership has not, however, been palatable to some libraries and therefore alternative models of shared or cooperative storage have emerged. This paper will review the development of the CARM Centre, a collaboratively owned and managed Australian store, as it has progressively moved away from a business model based on ceded ownership and introduced more flexible storage options in order to respond to the needs and circumstances of member libraries. The focus is to firstly understand why the CARM Centre was initially based on an integrated collection with ceded 
ownership, and then why the subsequent expansion of the service has been based on a principle of separate storage with ownership retained by member libraries.

\section{Ceded v Retained Ownership}

One of the persistent problems in managing or operating collections on a collaborative basis is that individual libraries and librarians will only be attracted into such schemes if there are likely to be immediate and local benefits for their own library's collections and services. Collaborative schemes often require upfront investment coupled with a leap of faith that the benefits will in turn flow to either (or preferably both) the library concerned and to the wider library network. This is particularly the case for larger libraries, as they often carry the greater part of the start-up costs and may have proportionally less to achieve in terms of benefits.

In terms of collaborative storage projects, larger libraries have been asked to make a psychological adjustment away from the long-established principle of collection selfsufficiency. For although even libraries with the largest collections would concede that the goal of self-sufficiency is no longer attainable, they nonetheless continue to value the prestige associated with being among the largest libraries in any given network, and continue to rely upon certain markers of their pre-eminence. Of these, perhaps none is more entrenched than that associated with collection size, which has long served as an indicator of a library's capacity to operate autonomously.

For these reasons some libraries continue to value retaining ownership of low-use research materials despite the system-wide pressures to minimise storage costs by implementing print repositories that depend for optimal efficiency and maximum cost-reduction on ceding ownership of stored items. The challenge to this model, however, has been the need to convince some libraries that it will be in their own interest to surrender ownership of items.

One of the challenges faced in discussing collaborative print storage is that it is not a single 'beast'. There is a bewildering array of models available; and the points of difference include management and ownership structures; funding arrangements; geographic scale; the types of materials included (i.e. journals only or journals and monographs); the creation of 'dark' or 'light' stores; and whether participation is confined to one library sector or open to all. So the question of whether ownership of stored items is retained or ceded is just one more point of difference, and to some extent the decision to 'retain or cede' is inter-related with these other decision points, in that matters of management structure, funding, geographic distribution and the categories of stored material will influence willingness to cede ownership. 
In the United States the various regional repositories serving major libraries such as PASCAL (Preservation and Access Service Center for Colorado); and ReCAP (Research Collection and Preservation Consortium) have tended to favour retention of ownership, while others serving smaller libraries (such as the Massachusetts based Five Colleges Consortium) rely upon ceded ownership. In Europe various models also apply; with the UKRR (United Kingdom Research Reserve) based on distributed storage and retained ownership; while the National Repository Library of Finland requires libraries to cede ownership. The repository storage system recently implemented by the Council of New Zealand University Librarians also requires ownership to be transferred to an independent body, Universities New Zealand.

From the advent of the concept of collaborative repository storage proponents have recognised the reluctance of some libraries to participate to the extent of ceding ownership of stored items. In one of the initial arguments made in favour of collaborative storage in 1980, German librarian Rolf Fuhlrott noted that:

[some of the] obstacles against [collaborative] storage arrangements are of a more psychological nature. Libraries are often concerned about their reputation diminishing if they withdraw materials, since the number of books and periodicals in a collection are still frequently taken as a measure of the importance of a library. $(1980,333)$

Fuhlrott went even further, however, noting that the reluctance may not only occur at an institutional level, but that individual librarians may be over-identifying with the prestige associated with their library and thereby making decisions that are effectively detrimental to their users and the wider information environment.

Many librarians-contrary to their own statements-are basically individualists, whose primary concern is their own institution. The library needs of their city, state or nation are only of secondary importance to them. (334)

When Michael Buckland took up the argument for collaborative print storage in the US a decade later he made a similar point when arguing that one of the reasons why libraries choose to retain 'little used duplicates' was due to the 'prestige' factor associated with large collections. Buckland argued that 'The raw numbers of volumes held is a deeply rooted index of library prestige and, other things being equal, it should be' (47). Buckland went on to 
contend, however, that libraries should be moving away from volume counts as an indicator of quality, and that assessment should move to a service-oriented approach that privileged access over ownership.

It is in the users' interest to move toward measures of the quality of service given and of the range of titles to which access is promptly provided wherever and however housed, and away from an indiscriminate counting of all volumes ever acquired. (1990, 47-48)

When Bernard Reilly undertook a comprehensive review of the state of co-operative storage in the US, his discussion of the role of individual libraries in co-operative programs and the part played by individual librarians focused on the mismatch of ambitions between librarians and the institutions they represented. Reilly argued that 'the appeal of co-operative repositories is often less compelling for library directors and staff than for university and state administrators', and concluded that libraries may be reluctant to consign ownership of items over to a repository on the basis that 'faculty reactions to the impact of removal of materials from campus shelves are normally directed at the library.' (2003, 39) Reilly went on to suggest that libraries are concerned not only with their relationship with their users but also with other libraries, and again touched upon the factor of the prestige associated with large collections, noting that 'for large libraries, the merging of holdings into shared collections can have a negative effect on a library's standing among its peers' (39).

In 2005 Scott Seaman published the results of a survey of four US university librarians facing a decision with regard to relinquishing ownership of print items to a shared repository. Consistent with Reilly's argument Seaman found that 'the issue of most concern to librarians was ownership of stored materials. There was a widespread perception among collection managers at the four institutions that jointly owned, off-site materials could not be considered part of local collections' $(2005,23)$. Contrary to the belief of these four librarians, however, Seaman found that although 'holdings counts were important for various statistical reporting' that nonetheless 'no accrediting body required library materials to be on campus for them to be counted as part of the collection' (23). Seaman did not pass judgement on whether the librarians were managing their collection in ignorance of the accrediting standards, or simply using the needs of accreditation as an excuse for their refusal to place print items in shared off-site storage.

The issue of library evaluation and accreditation was also taken up by Lizanne Payne in her major 2007 report on US print repositories, when she addressed the 'factors which may 
hinder development of a print repository network'. The first such factor that Payne noted was the use of 'Library and university evaluation criteria which assume a correlation between the size of local library collections and institutional support for research and scholarship'. She suggested a solution that would meet the demands of accreditation while also supporting the development of shared repositories.

\begin{abstract}
Evaluation of collection size (volume count) encourages unnecessary redundancy, and creates a disincentive to co-ordinate local holdings. To promote efficiency and cost-savings throughout the entire system, accrediting agencies and other evaluators could provide credit for once-owned materials which are still available through a formal agreement.
\end{abstract}

Accreditation per se is not an issue in the Australian context, where library collection size is not a direct component of any formal assessment process, but nonetheless there have been indications that some libraries continue to associate their reputation with collection size and to prize the local availability of little-used print material (Genoni, 2012). Despite protracted consideration by the Council of Australian University Librarians (Genoni, 2007) with regard to various approaches to shared print storage, little has been achieved outside of the Victorianbased CARM Centre that is the focus of this paper. It is notable that two universities based in New South Wales - Macquarie University and the University of Technology Sydney have recently elected to install, at considerable expense, on-site Automated Storage and Retrieval Systems as a means of retaining independent storage of legacy print items. In the face of these developments, it seems likely that the CARM Centre will remain unchallenged as Australia's only significant print repository, and it is therefore imperative that it provides a responsive service geared to the needs of its members.

\title{
The CARM Centre
}

The CARM (CAVAL Archival and Research Materials) Centre, an environmentally controlled repository designed for the long term storage of print materials, began operations in July 1996. This was a significant achievement for CAVAL, which at that time stood for 'Cooperative Action by Victorian Academic Libraries', although the full name is no longer used as the membership has expanded to include libraries from outside Victoria. The emphasis on 'co-operative action' has, however, been retained and recalls the vision that the founding members had of activities and programs that were genuinely co-operative and collaborative. Within a few years of CAVAL's birth in 1978, an ambitious but staged strategy for resource- 
sharing programs was well documented in internal documents and published annual reports. The first shared program was a reciprocal borrowing program which commenced as a pilot in 1979 and still operates today. Other components of the resource-sharing strategy included a shared union catalogue and a 'shared storage' facility.

The concept of a shared storage facility was thoroughly explored by CAVAL over several years through the commissioning of a feasibility study; a careful review of overseas developments; the documentation of a range of possible business and operational models, and the consideration of funding possibilities. The securing of funding from the Commonwealth Government in 1993 along with matching pledges from the majority of member libraries enabled the CAVAL Consortium to move from a concept to a project. Following confirmation that La Trobe University's contribution was to be the provision of land on its Bundoora campus along with expertise to manage the project, a steering committee was established and architects engaged. Additional funding from the Victorian State Government enabled the construction of a larger facility with a proportion of the additional space allocated for use by the State Library of Victoria.

The facility was designed for both operations and space utilisation to be managed as economically as possible. This would be achieved by storing items in a high density configuration with books sorted by size, placed in specially designed trays, and tracked using a modified warehouse management system. Additionally it was agreed that the collection, now known as the CARM Shared Collection, would be owned by the consortium. Therefore any duplicated items deposited with the Shared Collection could be discarded, with the collection retaining 'last copies'. At the time of deposit of materials, ownership would be ceded from the depositing library to the CAVAL consortium. Each participating library was allocated space in proportion to the financial contribution made by their institution, and in addition each agreed to contribute towards annual maintenance costs in the same proportion. The retention of these last copies enabled other member libraries to discard duplicates of items ceded to the CARM Shared Collection, thus freeing up space within their own libraries.

Initially the take-up of space in the CARM Centre was slow. Each member library took some time to develop policies and procedures for the selection and transfer of items to CARM and the consequential ceding of ownership. Some of the issues addressed included consultation and communication with academic staff about the benefits for the university and the library, and re-assurance that the transfer of ownership would not affect access. The CARM Centre Advisory Committee, consisting of representatives from each member library, worked closely 
with CARM Centre staff on the implementation of discovery and access procedures. A commitment was made to scan and deliver materials digitally, or ship physical items within 24 hours of a request being placed. The cost of all inter-library loans and document delivery from the CARM Shared Collection is free to participating libraries. In addition the facility includes a reading room where researchers can use material on-site, and the collection is made available to the wider library community through the inter-library loan network.

The chart in Figure 1 below indicates the current allocation of space in the CARM Shared Collection by each of the participating member libraries. All but two CAVAL Member Libraries (the Australian Catholic University and the University of Tasmania) have contributed to the Shared Collection to a greater or lesser extent.

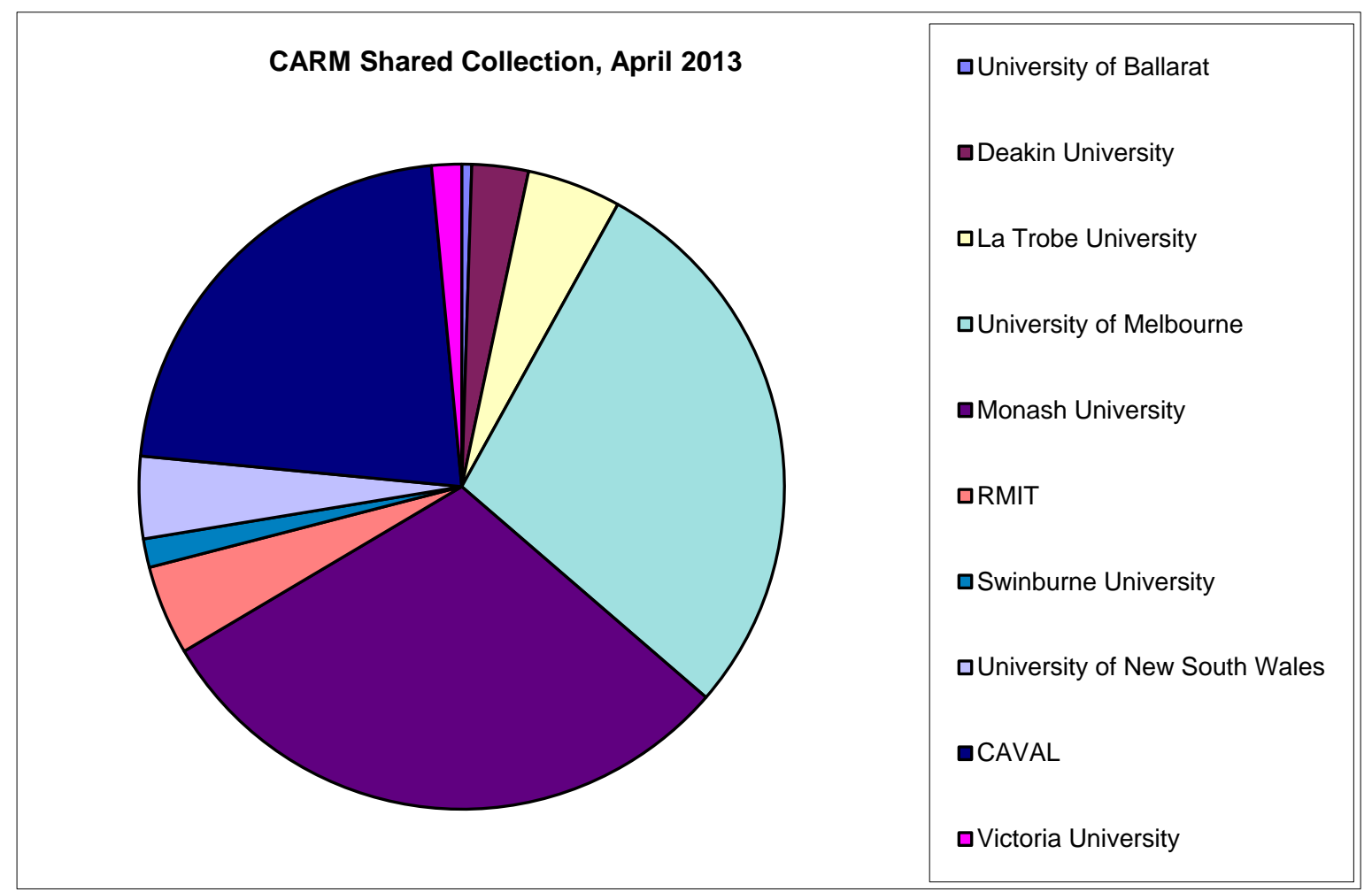

Figure 1 - CARM Shared Collection: Participating Libraries and Space Allocation

While the rate of deposit gradually increased, it also became obvious over several years that the continued reliance on volume counts by some of the larger libraries was having a detrimental impact on the potential growth of the CARM Shared Collection. For although the collection grew to over 400,000 volumes, the reluctance by some libraries to cede ownership and to pursue instead a policy of shared storage based on retained ownership was hindering the implementation of the repository-based solution. As Steve O'Connor, a former CEO of CAVAL noted: 
The difficulty of consigning ownership of material away from the parent institution has, in many systems, real impacts. Where there is a culture of measuring quality through a volume count, then any diminution of total volumes can prove to be a difficulty. The CARM Centre philosophy is that an institution is not giving up the ownership of a volume but taking collective ownership of a whole collection. $(2004,56)$

An emerging factor with regard to libraries choosing to retain ownership was that their parent institutions were increasingly seeking to attain a high profile through the various national and international 'rankings' that are now given to universities. That these rankings are often undertaken on an international scale creates pressure on universities in a mid-ranking nation-in terms of academic library collection size-such as Australia. In order to compete with the larger international universities there is an incentive for them to retain ownership of as much print material as possible, irrespective of the additional costs this might impose on a university. As Wright, Jilovsky and Anderson (2012) noted with regard to the hesitant development of the CARM Centre Collection:

One of the major contributing institutions to the Centre placed a high value on their place in worldwide university rankings, particularly those which consider physical collection size as part of the ranking methodology. As a result, there was a direct incentive to maintain ownership and collection size while there was still a need to provide for collection growth and student space without increasing building size. (288)

Wright, Jilovsky and Anderson also concluded that some libraries were reluctant or unable to cede ownership of items that retained a notional asset value in the owning university's financial systems. While this may be the case as a matter of institutional policy, it ignores the reality of the substantial costs associated with retaining long-term ownership of low-use print items. And while that cost might be notionally justified in terms of providing high-level service to local users, the reality is that libraries that choose this path will increasingly be sustaining the performance of other libraries that choose to rely upon access rather than ownership. As some mid-size Australian university libraries choose to maintain 'steady-state' collections based on a constant program of disposal (Genoni, 2008), then the larger libraries electing to retain ownership will inevitably carry a disproportionate amount of the system-wide costs required to store low-use material. 
By 2005, after almost ten years of operations, the CARM Centre was nonetheless filling, and CAVAL began to explore the need and possibilities for expansion. This planning was undertaken with the awareness that the library and research environment had changed in many significant ways over the past decade. Access and usage of electronic collections had moved from a possibility to a reality, and the focus of library staff was very much on digital rather than physical storage. Physical spaces within libraries had been re-modelled and reenvisaged for new collaborative student spaces and technology based learning commons. And although as noted greater competitiveness and changed institutional priorities had made member libraries reluctant to continue ceding items into the CARM Shared Collection, several of the larger libraries in particular had an urgent need for off-site storage space in order to continue their re-organisation of on-site library spaces.

In 2007 a feasibility study was undertaken, which predicted a need for more than 60 kilometres of additional shelving capacity over the next 20 years. Planning for the expansion of the CARM Centre to meet this need became known as the CARM2 Project. The planning process included a review that assessed the alternative strategies that could be considered by a member university for the storage of lesser-used research materials. Nine options were developed and each was analysed to evaluate the financial and non-financial impacts based on quantitative, qualitative and risk management criteria. These options included digitising and discarding all low use materials; constructing an on-campus storage facility; moving collections to a commercial storage provider; collaborating with other members in the construction of a shared facility; and a 'do nothing' option-that is, retaining materials within the university library. The analysis demonstrated that a shared storage facility would best meet the qualitative needs of a member university library, and that this option would minimise the set-up and operational costs, and require the lowest initial capital outlay (Wright, Jilovsky, Anderson 2012).

Those member libraries with the greatest need for space made clear that they were no longer willing to cede ownership of items to the shared collection, but instead required individual storage space within a shared facility. Alternative business models were therefore explored, based on an expanded facility in which ownership could be retained of the stored collections. The immediate need therefore was to implement a form of storage that allowed for separate location of collections. As a result a concept of a 'medium density' storage configuration was proposed, where items would be placed in 'library-like' sequence as per standard shelving, but without gaps, and on shelves wide enough for double rows of books. Researchers would be able to visit and physically browse the collections, and items would not need sorting and processing - instead materials could be efficiently retrieved from library 
shelves by removalists, transported to the CARM Centre and placed directly onto the CARM2 shelves. This concept was welcomed as a cost-effective and practical alternative to the CARM Shared Collection high-density model.

Discussions with interested libraries indicated that the provision of capital funding for the CARM2 project was the most viable option. A business model based on upfront capital contributions from participating libraries in return for an allocation of space within the facility and long term discounts on annual maintenance fees was developed and costed. The model incorporated a portion of the shelving space being un-allocated and available to CAVAL for lease to other libraries and customers. Three member libraries - Monash University, the University of Melbourne and RMIT University - indicated that this model was acceptable and formal offers were drawn up. In exchange for a contribution to the capital costs of CARM2 each institution received licensed space for a 30 year period. The acceptance of this offer by these three institutions enabled CAVAL to commence detailed planning for the design and construction of a second storage module for the CARM Centre. The CARM2 module was completed in November 2010 at a cost of \$AUD14 million (Wright, Jilovsky, Anderson 2012; Jilovsky 2012).

In addition to the new model of medium density or 'library-like' storage, a modified highdensity model was also offered. The high-density option incorporated payment of a processing fee for materials to be de-duplicated, re-catalogued, sorted and boxed by size, but the depositing library would retain ownership and the boxes would be stored in the member libraries licenced or leased space. Monash University elected to take up this option, while the University of Melbourne and RMIT University opted for the medium density storage approach.

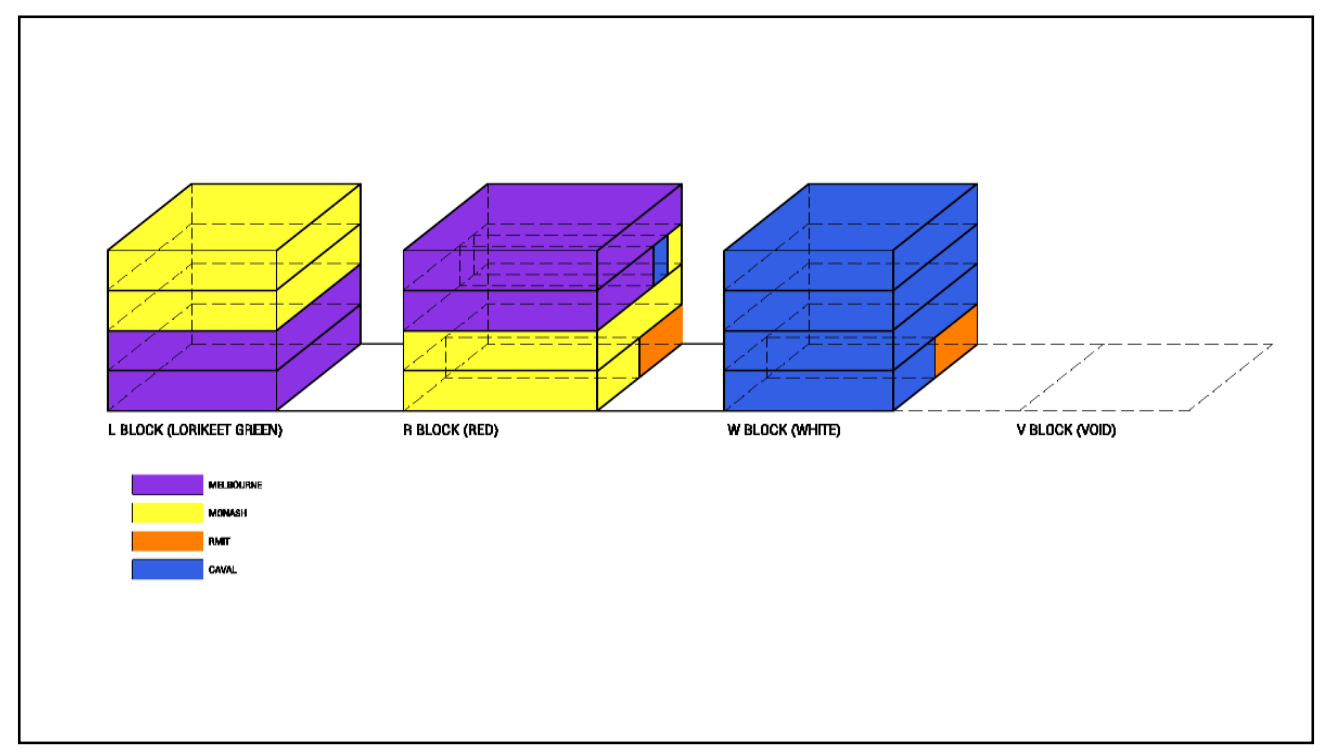


Figure 2 shows the space allocation within the CARM2 facility. The shelving has been constructed in 4 blocks (designated L, R, W and V), each with 4 levels. Space was allocated to each of the 3 capital partners (Monash University, RMIT University and the University of Melbourne) in proportion to the amount contributed by each institution. It can be seen that this allocated space encompasses all of ' $L$ ' block and 'R' block and a small portion of ' $W$ ' block. The remaining space in 'W' block is available to CAVAL to lease to other customers, with the income received going towards repayment of the bank finance and the building up of reserves for the construction of additional shelving in the $4^{\text {th }}$ ' $V$ ' block in 10 to 15 years time, when it is expected that the other shelved space will have been exhausted. This $4^{\text {th }}$ block, also known as the 'Void' is currently being used for the storage of artwork and museum artifacts from cultural collections of CAVAL member institutions.

As at April 2013, Monash University has filled $40 \%$ of their allocated space which has been processed into high density. The Monash University Materials are a mixture of monographs and journals and the average density achieved is 85 volumes per linear metre. The University of Melbourne and RMIT University are both storing materials at medium density. the University of Melbourne has filled $74 \%$ of their space and RMIT's space allocation is $100 \%$ full. There are considerable variations in the actual 'medium density' densities achieved within the RMIT and the University Melbourne's collections stored in CARM2. The average for monographs is between 80 to 90 volumes per linear metre and for journals 40 to 50 volumes per linear metre.

One crucial element with regard to decision making for long-term print storage has been the paucity of accurate data regarding the costs of competing forms of storage. In recent years some better data has begun to emerge, for example, the ReCAP group of libraries in the United States, indicate an annual cost of USD 86 cents per item in a print repository (Malpas 2011). In contrast, the per annum cost of items stored in on-campus library collections has been calculated as \$US4.25 (Courant and Nielsen 2010). Based on CAVAL financial data and CARM space utilisation and density data, the average cost of storing items (in 2012 AUD dollars) in the CARM Shared Collection is 60 cents per item per year. It should be noted that this excludes the processing costs paid by each contributing library when materials are deposited.

For collections stored in CARM2, the costs vary according to whether the institution has contributed capital funding or leases space on an annual basis, and whether the items are 
placed into high density (therefore incurring an upfront processing cost) or are stored in a 'library-like' medium density configuration.

\begin{tabular}{lllll} 
CARM2 STORAGE COST PER VOL PER YEAR & \multicolumn{5}{l}{ Years of storage } \\
Configuration & 10 & 20 & 30 & 50 \\
Capital contribution, High Density & $\$ 1.30$ & $\$ 0.62$ & $\$ 0.50$ & $\$ 0.41$ \\
Capital contribution, Medium Density & $\$ 1.43$ & $\$ 0.69$ & $\$ 0.57$ & $\$ 0.47$ \\
Leased Space, High Density & $\$ 0.84$ & $\$ 0.78$ & $\$ 0.77$ & $\$ 0.75$ \\
Leased Space, Medium Density & $\$ 0.89$ & $\$ 0.89$ & $\$ 0.89$ & $\$ 0.89$
\end{tabular}

Table 1 - CARM2 Storage Cost Per Volume Per Annum

Table 1 indicates that the longer the period that items are stored in CARM2, the cheaper the annual cost becomes. For thirty years or more, the annual cost per item is 50 cents or less per item per year in high density licensed space or 57 cents or less per item per year in medium density licensed space. These figures assume that the available space is taken up within the first ten years, so that all processing costs are paid during this period and that the capital contribution has been paid up-front in one lump sum.

For member libraries that take up space through an annual lease agreement instead of an up-front capital contribution, the annual cost in the long term is still considerably cheaper than in-library costs, for example 89 cents per item per year to store items in the medium density configuration.

\section{The Yin and Yang of the CARM Centre}

The concept of Yin and Yang can easily be applied to the CARM Centre. Although CARM1 and CARM2 were designed and built only fourteen years apart, and both provide shared storage of print collections, each has a different focus and business model. The concept for the CARM Shared Collection was based on de-duplication in order to save space and realise the best economic outcome for the consortium, whereas the CARM2 model was developed to meet the preferred strategies of individual libraries whilst utilising the benefits of a shared facility. However, as a whole they are interconnected and interdependent within the facility, and libraries can and have taken up either one or both options. The CARM Shared Collection could potentially be expanded into CARM2 space, should some or all member libraries choose this and are prepared to provide funding.

The CARM Centre demonstrates that variant models for storage configurations and collection ownership can co-exist and meet the differing needs of member libraries within one facility. It is unlikely that - in the Australian context at least - it would be possible to 
proceed with a single model that would meet the needs of all academic libraries. There are almost forty university libraries in Australia, and these are of quite different sizes and with quite different histories and goals, and have different amounts of space available on existing campus sites. Therefore, the need for off-site storage and the terms and conditions under which they are willing to accept it will also differ. CAVAL, in implementing more flexible storage options for the CARM Centre is responding to the expressed wishes of its members.

It is also the case that the storage decisions libraries take are increasingly capable of being supported by local library systems. A new generation of library systems are beginning to be implemented across academic and research libraries and are being used as an opportunity to review and streamline operations and to harness the benefits of sophisticated technologies. Whilst it is unlikely to be economic to merge or physically de-duplicate collections already placed into storage, potentially this could be done virtually. In this scenario the emphasis could be much more on discoverability and access to the deduplicated collections rather than on ownership or physical location.

\section{Conclusion}

As academic and other research libraries continue the transition from print to digital they will face ongoing challenges and decisions regarding the management of legacy print collections. As has long been the case, these decisions will be made on the basis of both meeting the needs of an immediate user group coupled with an awareness of the impact on wider networks of libraries and the broader user community. Libraries will also face decisions that ask them to balance the need to incur immediate costs or to defer decisions (and the short term expense) in favour of delayed action that might involve greater long term cost. Further complexity is introduced by the ever changing technology that constantly threatens to make today's decisions redundant.

In few areas are the challenges with regarding to building future collections and services more apparent than with the management of legacy print material. Common-sense and a growing body of evidence suggest that the more collaborative the approach to this task the better the outcome in terms of both service and long-term costs, and that as the transition from print to digital continues then the pressure to reduce the cost of indefinite local storage of low-use research material will escalate. At present, however, there remain other drivers that lead libraries to take a conservative approach to print management, including the retention of duplicated low-use items. 
CAVAL has long attempted to adopt a leadership role as Australian libraries have made the transition from shared collections to shared storage, and in doing so has both championed collaboration while taking a pragmatic approach in recognising its limits. These limits have inevitably been reached by a number of libraries as they function in a higher education system that encourages both co-operation and competition, and as they grapple to get the management of their legacy print collections 'right' in the face of conflicting goals related to cost and service, and attempt to marry their local priorities with responsibilities to wider library networks. . In these circumstances CAVAL's approach has been, and continues to be, that each member library makes its own decision and that CAVAL's role is to facilitate those decisions while retaining an approach that supports network-wide solutions, be this in the form of a fully integrated and independently owned collection, or a co-ordinated and carefully managed shared storage facility. 
ARL Statistics and Assessment Committee. 2007. 'New ways of measuring collections: an implementation plan'. Washington: Association of Research Libraries.

Buckland, M. K. 1990. "Little used duplicates, cooperative collection development, and storage”, Collection Management, Vol. 13 No 4, pp. 39-52.

Courant, P. M. and M. Nielsen. 2010. "On the cost of keeping a book". In The Idea of Order: Transforming Research Collections for the Twenty-first Century, 81-105. Council on Libraries and Information Resources, Washington, D.C., available at:

http://www.clir.org/pubs/reports/pub147/reports/pub147/pub147.pdf (accessed 5 March 2013).

Fuhlrott, R (1980),. "Cooperative storage: lightening the burden of libraries", Libri, Vol 30 No 4, pp. 321-337.

Genoni, P. (2007), "Towards a national print repository for Australia: where from and where to?", Australian Academic and Research Libraries, Vol 38 No 2, pp. 84-98.

Genoni, P. (2008) "Current and future print storage for Australian academic libraries: results of a survey". Library Collections, Acquisitions \& Technical Services, Vol 32 No 1, pp. 31-41.

Genoni, P. (2012), "Storage of legacy print collections: the views of Australasian university librarians", Collection Management, Vol 37 No 1, pp. 23-46.

Jilovsky, C. (2012), "The CARM2 print repository: from planning to operations", paper presented at the IFLA Satellite Conference: Global Policies, Imperatives and Solutions for the Efficient Print Resources Management and Access to Less Used Documents, August 110, Kuopio, Finland: August 1-10, available at:

http://www.nrl.fi/ifla2012/kuopiosatellite/Papers/Jilovsky.pdf. (accessed 5 March 2013).

Malpas, C. (2011), "Cloud-sourcing research collections: managing print in the massdigitized library environment". OCLC Research, Dublin, Ohio, available at:

http://www.oclc.org/research/publications/library/2011/2011-01.pdf (accessed 6 March 2013).

O'Connor, S. (2004), "Collaborative strategies for low-use research materials", Library Collections, Acquisitions \& Technical Services, Vol 28 No 1, pp. 51-57.

Payne, L. (2007), "Library storage facilities and the future of print collections in North America”, OCLC, Dublin, Ohio

Reilly, B. F. (2003), Developing Print Repositories: Models for Shared Preservation and Access. Washington: Council on Library and Information Resources. Accessed March 7, 2013. http://www.clir.org/pubs/reports/pub117/pub117.pdf

Seaman, S. (2005), "Collaborative collection management in a high-density storage facility", College \& Research Libraries, Vol 66 No 1, pp. 20-27.

Wright, J., Jilovsky, C. and Anderson, C. (2012), "The story of a shared last copy repository in Australia: the CARM Centre Stage 2 development", Collection Management Vol 37 No 3/4, pp. 271-293.(3-4): 271-93. 